\title{
The Application of Quadratic Optimal Cooperative Control Synthesis to a $\mathrm{CH}-47$ Helicopter
}

\section{Barbara K. Townsend}

(NASA-TE-8835引) THE ARPLICAIICN OF

CUADRATIC CPTIMAI COCFERATIVE CCATECL

SYNTHESIS TO A CE-47 HEIICCETFE (NASA) $23 p$
N87-17715

Unclas

43510

September 1986

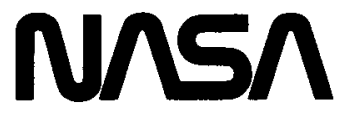

National Aeronautics and 
NASA Technical Memorandum 88353

\section{The Application of Quadratic Optimal Cooperative Control Synthesis to a $\mathrm{CH}-47$ Helicopter}

Barbara K. Townsend, Ames Research Center, Moffett Field, California

September 1986

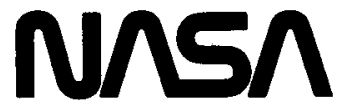

National Aeronautics and

Space Administration

Ames Research Center

Moffett Field, California 94035 


\title{
THE APPLICATION OF QUADRATIC OPTIMAL COOPERATIVE CONTROL SYNTHESIS TO A CH-47 HELICOPTER
}

\author{
Barbara K. Townsend \\ NASA Ames Research Center
}

\begin{abstract}
A control-system design method, Quadratic Optimal Cooperative Control Synthesis (CCS), is applied to the design of a Stability and Control Augmentation System (SCAS). The CCS design method is different from other design methods in that it does not require detailed a priori design criteria, but instead relies on an explicit optimal pilot-model to create desired performance. The design method, which was developed previously for fixedwing aircraft, is simplified and modified for application to a Boeing Vertol CH-47 helicopter. Two SCAS designs are developed using the CCS design methodology. The resulting CCS designs are then compared with designs obtained using classical/frequency-domain methods and Linear Quadratic Regulator (LQR) theory in a piloted fixed-base simulation. Results indicate that the CCS method, with slight modifications, can be used to produce controller designs which compare favorably with the frequency-domain approach.
\end{abstract}

\section{NOMENCLATURE}

\section{Matrix Definitions}

A helicopter dynamics matrix

$A$ augmented helicopter dynamics matrix

B helicopter control effectiveness matrix

$B \quad$ augmented helicopter control effectiveness matrix

Ba $_{a} \quad$ pilot-model helicopter control effectiveness matrix

$\mathbf{B}_{p} \quad$ SCAS helicopter control effectiveness matrix

$\mathrm{C}_{p} \quad$ pilot-model state observation matrix

$\mathrm{C}_{u} \quad$ SCAS control measurement matrix

$\mathrm{C}_{\boldsymbol{x}} \quad$ SCAS state measurement matrix

D helicopter disturbance input matrix

F $_{1}$ pilot-model control input weighting matrix (SCAS objective function)

$\mathbf{F}_{2}$ pilot-model control rate input weighting matrix (SCAS objective function)

$\mathbf{F}_{3} \quad$ SCAS control input weighting matrix (SCAS objective function)

$\mathbf{F}_{p} \quad$ pilot-model total state estimator gain matrix

$\mathbf{F}_{\mathbf{u}} \quad$ pilot-model state estimator gain matrix (on pilot control)

$\mathbf{F}_{\boldsymbol{x}} \quad$ pilot-model state estimator gain matrix (on aircraft state)

G LQR feedback control gain matrix

$\mathbf{G}_{\mathbf{a}} \quad$ SCAS feedback and feedforward control gain matrix

$\mathbf{G}_{f b} \quad$ pseudoinverse additional feedback control gain matrix

$\mathbf{G}_{f f} \quad$ pseudoinverse additional feedforward control gain matrix

$\mathbf{G}_{\text {modified }}$ pseudoinverse total control gain matrix

$\mathbf{G}_{p} \quad$ pilot-model feedback and feedforward control gain matrix

$\mathbf{G}_{u} \quad$ pilot-model feedforward control gain matrix

$\mathbf{G}_{u u} \quad$ SCAS feedforward control gain matrix

$\mathbf{G}_{\boldsymbol{x}} \quad$ pilot-model feedback control gain matrix

$\mathbf{G}_{x \boldsymbol{x}} \quad$ SCAS feedback control gain matrix

R control displacement weighting matrix (LQR objective function) 


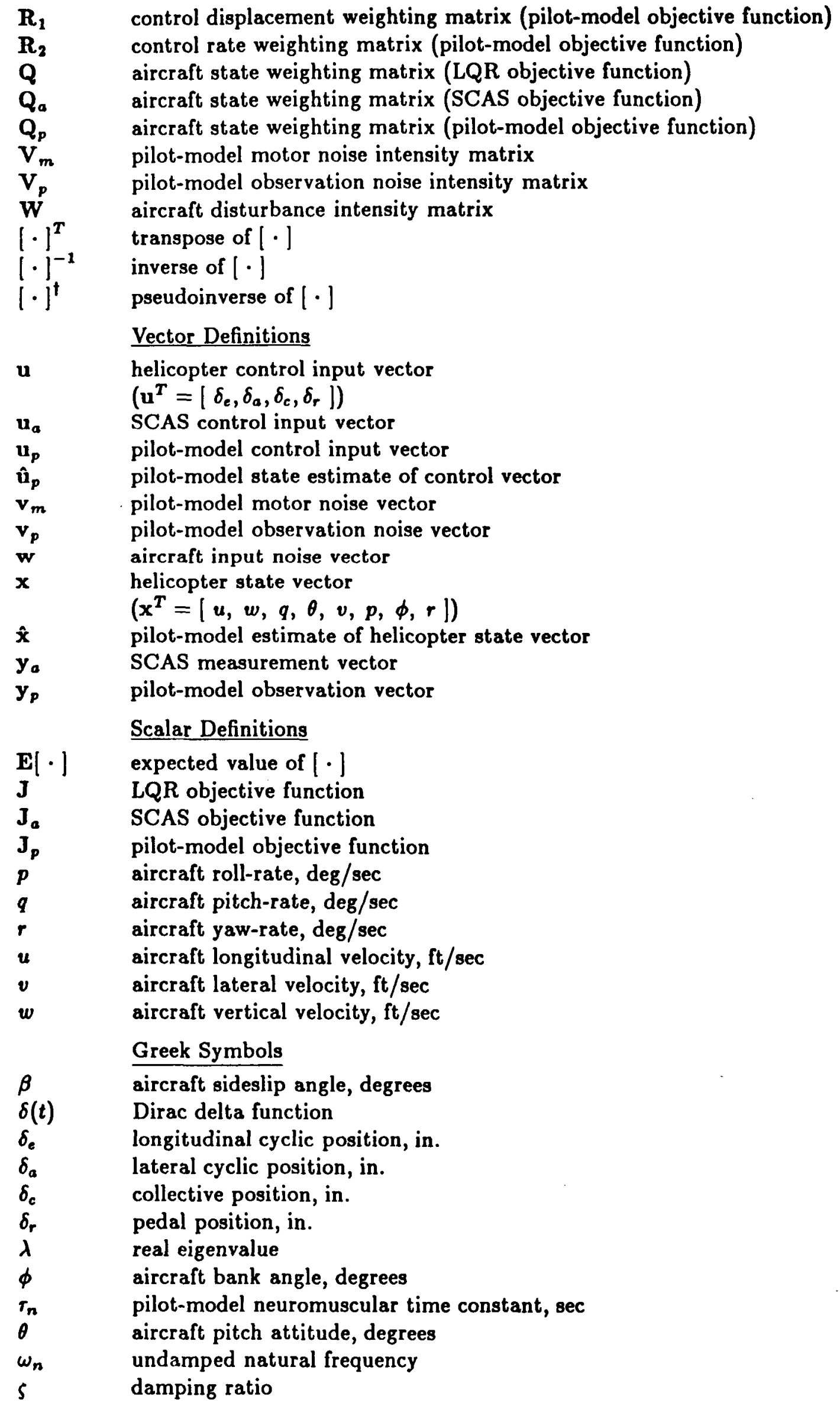




\section{INTRODUCTION}

In the past, the predominant method for Stability and Control Augmentation System (SCAS) design has been a frequency-domain based approach, in which suitable input-output characteristics are obtained by matching desired transfer functions using root-locus techniques. Although this approach has proven to be a very reliable and successful technique, there are disadvantages which become apparent when applied to more complex aircraft with higher degrees of coupling. Recently, there has also been increased interest in a more integrated approach to control-system design, in which several automatic controllers in an aircraft are designed to work together instead of autonomously. Frequency-domain techniques are difficult to apply in this situation because of their single-input, single-output nature.

These trends have led towards a more algorithmic, or automatic, approach to controlsystem design. One area that has received a great deal of attention in recent years has been Linear Quadratic Regulator (LQR) theory. Although LQR theory is well suited to the design of autopilots in aircraft or structural control design, it is not always adequate for SCAS design since the theory automatically leads to a stable closed-loop system. Successful SCAS design requires adequate closed-loop stability and proper pilot control response; basic LQR theory does not provide a direct means to meet the latter requirement.

Another control design technique which utilizes LQR theory is model-based compensation (ref. 1), in which LQR theory is used to minimize differences between aircraft states and states of a math model which possesses the desired characteristics. Although this still promises to be a very useful and powerful design method, there are some serious disadvantages. First, the design method requires detailed a priori knowledge of the desired aircraft response. Second, the structure of the control design requires on-line calculation of the model states for the control law implementation. Finally, like most LQR-based designs, it usually requires state feedback, making an estimator necessary. The combination of the model and the estimator leads in most cases to a very high-order control-system, requiring sophisticated computer equipment to do the on-line computation necessary for the controller implementation.

Quadratic Optimal Cooperative Control Synthesis (CCS) is a control design method which also uses LQR theory, but it offers two distinct features. First, it leads to a very simple measurement feedback controller design. Second, it requires no detailed a priori design criteria, because an assumed analytic pilot-model structure is an inherent feature of the approach. This can be a great advantage in cases where no existing design criteria exist because of either the nature of aircraft being controlled, or of the task being performed. The need for explicit a priori design criteria is eliminated through the use of an explicit optimal pilot-model; all that is necessary is a description of the desired task.

Previously, the CCS method was used to design a SCAS for the longitudinal dynamics of the AFTI/F-16 aircraft (ref. 2). When evaluated in a fixed-base simulation, this CCS design was found to compare favorably with the augmentation currently being used on the F-16. The purpose of the work described in this paper was to investigate the feasibility of using CCS methodology for control augmentation design in helicopters. To do this, it was necessary both to simplify and modify the design process for application to a different class of flight vehicle. Two different SCAS controls were designed using the CCS method on a helicopter; two other controllers were designed using LQR and frequency-domain methods. The resulting control-systems were then compared in a piloted fixed-base simulation.

The remainder of this paper describes the CCS methodology, the experiment design and conduct, and the results and conclusions of the experiment. 


\section{CCS DESIGN METHOD}

For optimal control design methods, a controller is sought which will minimize some type of objective function. As an example, in LQR theory, a quadratic sum of plant states and control inputs is minimized. Similarly, in model-based compensation, a quadratic sum of errors between the model and plant states, and the control inputs is minimized. Cooperative Control Synthesis (CCS) is also based on minimizing an objective function, but it differs from these other two methods in what is defined to be minimized.

The basic CCS design structure is shown in figure 1 . This method incorporates an optimal pilot-model with the aircraft model; then a quadratic sum of aircraft states, control inputs, and pilot states is minimized. Another advantage of CCS over other optimal control design methods is the use of measurement (or output) feedback rather than full state feedback (for the control design).

The CCS design method is an iterative procedure in which the simultaneous solution of both the optimal pilot-model equations and output feedback equations is obtained. The solution method is iterative because of the use of output rather than state feedback; this will be discussed in more detail later in the paper. The basic design steps are described below:

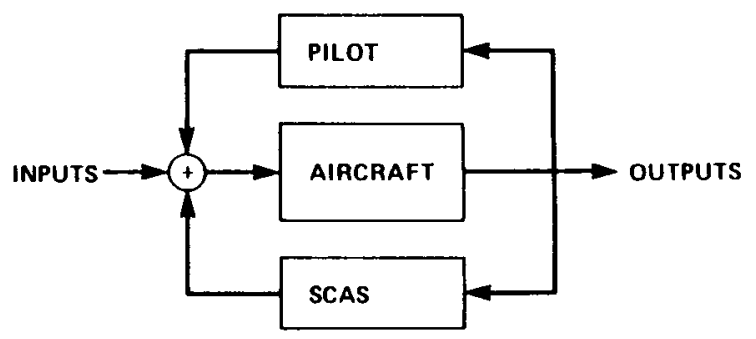

Figure 1 - CCS Design Structure

1) The optimal pilot-model solution is obtained for control of the augmented aircraft (on the first iteration of the design, the aircraft augmentation is set to zero)

2) The LQR output feedback solution is obtained for the total aircraft/pilot-model system.

3) Steps 1 and 2 are repeated until a stationary solution is obtained.

The aircraft model, optimal pilot-model, SCAS solution, and design method simplifications and modifications are described in the following sections.

\subsection{Aircraft Model}

The linearized aircraft dynamics can be expressed in terms of the relation:

$$
\dot{\mathbf{x}}=\mathbf{A} \mathbf{x}+\mathbf{B}_{\mathbf{p}} \mathbf{u}_{\mathbf{p}}+\mathbf{B}_{\mathbf{a}} \mathbf{u}_{\mathbf{a}}+\mathbf{D} \mathbf{w}
$$

$$
\text { where } \begin{aligned}
\mathbf{x} & =\text { aircraft states } \\
\mathbf{u}_{\mathbf{p}}= & \text { pilot control inputs } \\
\mathbf{u}_{a}= & \text { aircraft controller inputs } \\
\mathbf{w}= & \text { aircraft disturbance (a zero mean Gaussian white noise } \\
& \text { process with intensity } \left.\mathbf{W} ; \mathbf{E}\left\{\mathbf{w}(t) \mathbf{w}^{T}(\tau)\right\}=W \delta(t-\tau)\right)
\end{aligned}
$$

and $\mathbf{A}, \mathbf{B}_{p}, \mathbf{B}_{a}$, and $\mathbf{D}$ are constant matrices of appropriate dimensions. All of the vectors described above are perturbations about the trimmed aircraft states and control positions. The SCAS control law $u_{a}$ and feedback measurements $y_{a}$ are expressed as:

$$
\begin{gathered}
\mathbf{u}_{a}=\mathbf{G}_{a} \mathbf{Y}_{a} \\
\mathbf{y}_{a}=\mathbf{C}_{x} \mathbf{x}+\mathbf{C}_{\boldsymbol{u}} \mathbf{u}_{p}
\end{gathered}
$$

where $\mathbf{C}_{\boldsymbol{x}}$ and $\mathbf{C}_{u}$ are constant gain matrices representing the combination of aircraft states and control positions available for measurement and feedback, and $\mathbf{G}_{a}$ is the constant feedback and feedforward gain matrix. Substituting equations (2) and (3) into equation (1) yields the augmented aircraft dynamics:

$$
\dot{\mathbf{x}}=\left(\mathbf{A}+\mathbf{B}_{a} \mathbf{G}_{a} \mathbf{C}_{x}\right) \mathbf{x}+\left(\mathbf{B}_{p}+\mathbf{B}_{a} \mathbf{G}_{a} \mathbf{C}_{u}\right) \mathbf{u}_{p}+\mathbf{D w}
$$


Simplifying equation (4) results in:

$$
\dot{\mathbf{x}}=A \mathbf{x}+B \mathbf{u}_{p}+\mathbf{D w}
$$

where $A=A+B_{a} \mathbf{G}_{a} \mathbf{C}_{x}$

$B=\mathbf{B}_{p}+\mathbf{B}_{a} \mathbf{G}_{a} \mathbf{C}_{\mu}$

\subsection{Optimal Pilot-Model}

Pilot modelling has been a topic of research for many years. Some of the earliest work in pilot modelling consisted of modelling the pilot as a linear servo-mechanism. In this type of model structure, the pilot's behavior is attributed to that of a linear controller, with a remnant term included to express the portion of pilot behavior which is not consistant with the linear operation on the inputs (ref. 3). Some of the work based on this model premise has consisted of describing the pilot's behavior in terms of an optimal controller and state estimator (refs. 4, 5, and 6). As described in these refer-

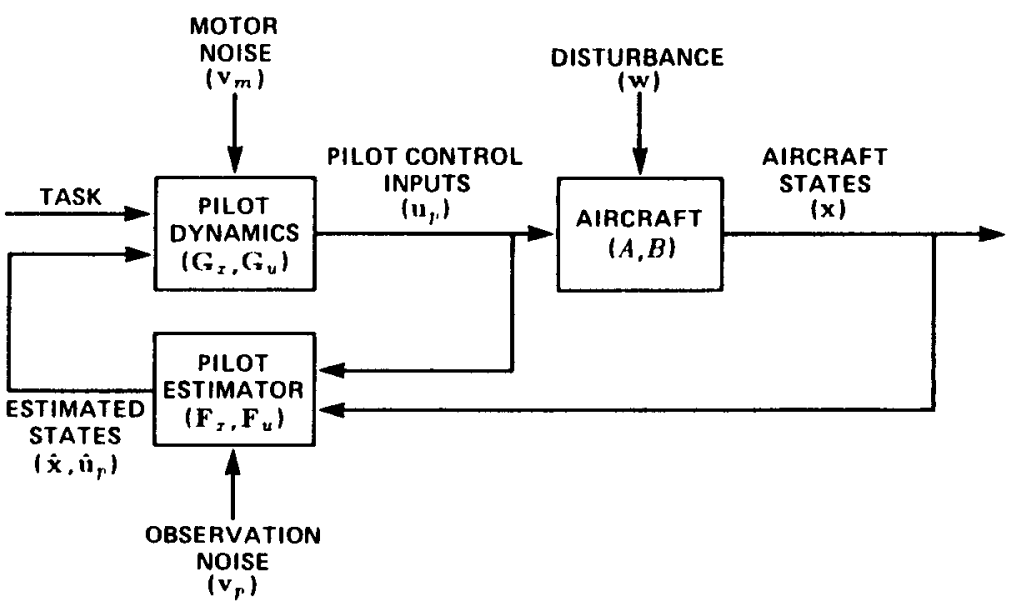
ences, one form of pilot-model (fig. 2) that correlates well with experimental data is:

$$
\begin{gathered}
\dot{\mathbf{u}}_{p}=\mathbf{G}_{x} \hat{\mathbf{x}}+\mathbf{G}_{u} \mathbf{u}_{p}+\mathbf{v}_{m} \\
\dot{\hat{\mathbf{x}}}=A \hat{\mathbf{x}}+B \hat{\mathbf{u}}_{p}+\mathbf{F}_{x} \mathbf{C}_{p}(\mathbf{x}-\hat{\mathbf{x}})+\mathbf{F}_{x} \mathbf{v}_{p} \\
\dot{\hat{\mathbf{u}}}_{p}=\mathbf{G}_{x} \hat{\mathbf{x}}+\mathbf{G}_{u} \hat{\mathbf{u}}_{p}+\mathbf{F}_{u} \mathbf{C}_{p}(\mathbf{x}-\hat{\mathbf{x}})+\mathbf{F}_{u} \mathbf{v}_{p} \\
\mathbf{y}_{p}=\mathbf{C}_{p} \mathbf{x}+\mathbf{v}_{p}
\end{gathered}
$$

where $\mathbf{u}_{p}=$ pilot's control inputs

$\mathbf{y}_{p}=$ pilot's observations

$\hat{\mathbf{x}}=$ pilot's estimate of aircraft states

$\hat{\mathbf{u}}_{p}=$ pilot's estimate of control positions

$\mathbf{v}_{p}=$ pilot's observation noise (a zero mean Gaussian white noise process of intensity $\left.\mathbf{V}_{p} ; \mathbf{E}\left\{\mathbf{v}_{p}(t) \mathbf{v}_{p}{ }^{T}(\tau)\right\}=\mathbf{V}_{p} \delta(t-\tau)\right)$

$\mathbf{v}_{\boldsymbol{m}}=$ pilot's motor noise (a zero mean Gaussian white noise process with intensity $\left.\mathbf{V}_{m} ; \mathbf{E}\left\{\mathbf{v}_{m}(t) \mathbf{v}_{m}{ }^{T}(\tau)\right\}=\mathbf{V}_{m} \delta(t-\tau)\right)$

$\mathbf{C}_{p}$ is a constant matrix defining the pilot's available observations, and $\mathbf{G}_{x}, \mathbf{G}_{u}, \mathbf{F}_{x}$, and $\mathbf{F}_{u}$ are constant matrices describing the pilot's feedback compensation and loop closures.

Consistent with the optimal pilot-model, the pilot is assumed to control the aircraft in a manner which minimizes some objective function $J_{p}$, expressible as:

$$
\mathbf{J}_{p}=\mathbf{E}\left\{\lim _{T \rightarrow \infty} \frac{1}{T} \int_{0}^{T}\left[\mathbf{x}^{T} \mathbf{Q}_{p} \mathbf{x}+\mathbf{u}_{p}{ }^{T} \mathbf{R}_{1} \mathbf{u}_{p}+\dot{\mathbf{u}}_{p}^{T} \mathbf{R}_{2} \dot{\mathbf{u}}_{p}\right] d t\right\}
$$


From the necessary conditions for optimality for the regulator and filter, $\mathbf{G}_{x}, \mathbf{G}_{u}, \mathbf{F}_{x}$, and $F_{u}$ must satisfy the following equations:

$$
\begin{gathered}
\mathbf{G}_{p} \equiv\left[\begin{array}{ll}
\mathbf{G}_{x} & \mathbf{G}_{u}
\end{array}\right]=-\left(\mathbf{R}_{2}\right)^{-1} \mathbf{B}_{1}{ }^{T} \mathbf{K} \\
\mathbf{0}=\mathbf{K} \mathbf{A}_{1}+\mathbf{A}_{1}{ }^{T} \mathbf{K}-\mathbf{K B} \mathbf{B}_{1}\left(\mathbf{R}_{2}\right)^{-1} \mathbf{B}_{1}{ }^{T} \mathbf{K}+\mathbf{Q}_{1} \\
\mathbf{F}_{p} \equiv\left[\begin{array}{l}
\mathbf{F}_{x} \\
\mathbf{F}_{u}
\end{array}\right]=\mathbf{P C}_{1}{ }^{T}\left(\mathbf{V}_{p}\right)^{-1} \\
\mathbf{0}=\mathbf{P}{\mathbf{A}_{2}}^{T}+\mathbf{A}_{2} \mathbf{P}-\mathbf{P C}_{1}{ }^{T}\left(\mathbf{V}_{p}\right)^{-1} \mathbf{C}_{1} \mathbf{P}+\mathbf{D}_{1} \mathbf{W}_{1} \mathbf{D}_{1}{ }^{T}
\end{gathered}
$$

and where $A_{1}, A_{2}, B_{1}, C_{1}, D_{1}, Q_{1}$, and $W_{1}$ are defined as:

$$
\begin{gathered}
\mathbf{A}_{1} \equiv\left[\begin{array}{ll}
A & B \\
0 & 0
\end{array}\right] \quad \mathbf{A}_{2} \equiv\left[\begin{array}{cc}
A & B \\
0 & \mathbf{G}_{u}
\end{array}\right] \quad \mathbf{B}_{1} \equiv\left[\begin{array}{ll}
0 & I
\end{array}\right] \quad \mathbf{C}_{1} \equiv\left[\begin{array}{ll}
\mathbf{C}_{p} & 0
\end{array}\right] \\
\mathbf{D}_{1} \equiv\left[\begin{array}{cc}
\mathbf{D} & 0 \\
0 & I
\end{array}\right] \quad \mathbf{Q}_{1} \equiv\left[\begin{array}{cc}
\mathbf{Q}_{p} & 0 \\
0 & \mathbf{R}_{1}
\end{array}\right] \quad \mathbf{W}_{1} \equiv\left[\begin{array}{cc}
\mathbf{W} & 0 \\
0 & \mathbf{V}_{m}
\end{array}\right]
\end{gathered}
$$

This pilot-model has been shown to correlate well with experimental results when $\mathbf{Q}_{p}$ is chosen to be representative of the pilot's task, and $R_{1}, R_{2}, V_{p}$, and $V_{m}$ are adjusted to satisfy two conditions. The first condition is related to the human neuromuscular time constant and the matrix $\mathbf{G}_{u}$. Considering initially a single-input, single-output case, the pilot control is of the form

$$
\dot{u}_{p}=g_{x} \hat{x}+g_{u} u_{p}+v_{m}
$$

where $g_{u}$ could be considered to be the negative inverse of the human neuromuscular lag time constant, or:

$$
\tau_{n}=-\frac{1}{g_{u}}
$$

Experimental correlation (ref. 4) has put $\tau_{n}$ in the range of .10 to $.25 \mathrm{sec}$. Extending this concept to the multi-input, multi-output case, it can be seen that the diagonal elements of the matrix $G_{u}$ should be within the range of -4 to -10 to reflect the desired motor time constants. $\mathbf{R}_{2}$ can be adjusted relative to $\mathbf{Q}_{p}$ to produce this result.

The second condition concerns the pilot remnant (ref. 3 ), or the relationship between pilot control output and pilot motor noise covariances, and pilot input and observation noise covariances. The work of Kleinman (ref. 5) shows that the following relationships lead to an appropriate representation of pilot remnant:

$$
\begin{gathered}
\mathrm{V}_{p}=\pi \rho_{u} \mathrm{E}\left\{\mathrm{y}_{p} \mathbf{y}_{p}{ }^{T}\right\} \\
\mathrm{V}_{m}=\pi \rho_{i} \mathbf{E}\left\{\mathbf{G}_{x} \hat{\mathbf{x}} \hat{\mathbf{X}}^{T} \mathbf{G}_{x}{ }^{T}\right\}
\end{gathered}
$$

where $\rho_{i}=.01$ and $\rho_{u}=.003$. Values for $V_{p}$ and $V_{m}$ are chosen relative to $W$ to satisfy these relationships. 


\subsection{Augmentation Control Solution (SCAS)}

As was previously mentioned, the SCAS is assumed to have the form given in equations (2) and (3). When the pilot-model described in equations (6) through (9) is included, the total closed-loop aircraft-pilot system can be written in state space notation as:

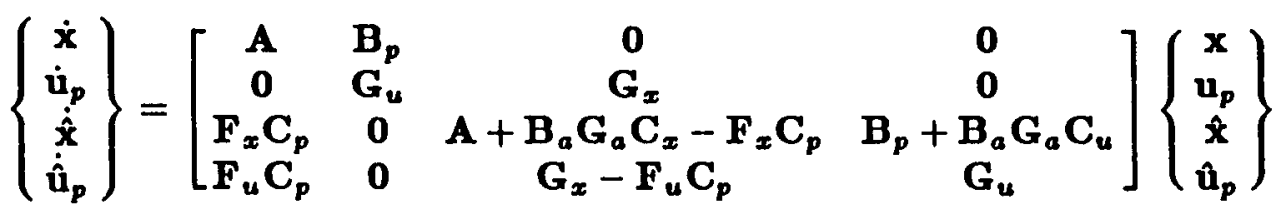

$$
\begin{aligned}
& +\left[\begin{array}{c}
\mathbf{B}_{a} \\
\mathbf{0} \\
\mathbf{0} \\
\mathbf{0}
\end{array}\right] \mathbf{u}_{a}+\left[\begin{array}{ccc}
\mathbf{D} & \mathbf{0} & \mathbf{0} \\
\mathbf{0} & \mathbf{I} & \mathbf{0} \\
\mathbf{0} & \mathbf{0} & \mathbf{F}_{\boldsymbol{x}} \\
\mathbf{0} & \mathbf{0} & \mathbf{F}_{u}
\end{array}\right]\left\{\begin{array}{c}
\mathbf{w} \\
\mathbf{v}_{m} \\
\mathbf{v}_{p}
\end{array}\right\} \\
& y_{a}=\left[\begin{array}{llll}
C_{x} & C_{u} & 0 & 0
\end{array}\right]\left\{\begin{array}{c}
x \\
\mathbf{u}_{p} \\
\hat{\mathbf{x}} \\
\hat{\mathbf{u}}_{p}
\end{array}\right\}
\end{aligned}
$$

The feedback gain matrix $\mathbf{G}_{a}$ is chosen to minimize a controller objective function $\mathbf{J}_{a}$, defined as:

$$
\mathbf{J}_{a}=\mathbf{E}\left\{\lim _{T \rightarrow \infty} \frac{1}{T} \int_{0}^{T}\left[\mathbf{x}^{T} \mathbf{Q}_{a} \mathbf{x}+\mathbf{u}_{p}{ }^{T} \mathbf{F}_{1} \mathbf{u}_{p}+\dot{\mathbf{u}}_{p}^{T} \mathbf{F}_{2} \dot{\mathbf{u}}_{p}+\mathbf{u}_{a}{ }^{T} \mathbf{F}_{s} \mathbf{u}_{a}\right] d t\right\}
$$

By defining $\mathbf{q}^{T}=\left[\begin{array}{llll}x^{T} & u_{p}^{T} & \hat{x}^{T} & \hat{u}_{p}^{T}\end{array}\right]$, we can rewrite equations (19), (20), and (21) as:

$$
\begin{gathered}
\dot{\mathbf{q}}=\overline{\mathbf{A}} \mathbf{q}+\overline{\mathbf{B}} \mathbf{u}_{\mathbf{a}}+\overline{\mathbf{D}} \overline{\mathbf{w}} \\
\mathbf{y}_{\mathbf{a}}=\overline{\mathbf{C}} \mathbf{q} \\
\mathbf{J}_{a}=\mathbf{E}\left\{\lim _{\mathbf{T} \rightarrow \infty} \frac{1}{T} \int_{0}^{T}\left[\mathbf{q}^{T} \overline{\mathbf{Q}} \mathbf{q}+\mathbf{u}_{a} T_{\mathbf{F}} \mathbf{w}_{\mathbf{a}}\right] d t\right\}
\end{gathered}
$$

where $\overline{\mathbf{A}}, \overline{\mathbf{B}}, \overline{\mathbf{D}}$, and $\overline{\mathbf{C}}$ and $\overline{\mathbf{w}}$ are corresponding matrices in equations (19) and (20), and:

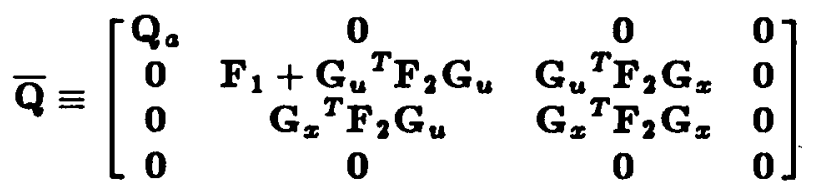

The minimizing solution $\mathbf{u}_{a}$ is (ref. 7 ):

$$
\mathbf{u}_{\mathbf{a}}=\mathbf{G}_{\mathbf{a}} \mathbf{Y}_{\mathbf{a}}
$$

where $\mathbf{G}_{a}$ satisfies the equations:

$$
\begin{gathered}
0=2 \overline{\mathbf{B}}^{T} \mathbf{K L} \overline{\mathbf{C}}^{T}+2 \mathrm{~F}_{3} \mathbf{G}_{a} \overline{\mathbf{C} L \overline{\mathbf{C}}^{T}} \\
0=\mathbf{L}\left(\overline{\mathbf{A}}+\overline{\mathbf{B}} \mathbf{G}_{a} \overline{\mathbf{C}}\right)^{T}+\left(\overline{\mathbf{A}}+\overline{\mathbf{B}} \mathbf{G}_{a} \overline{\mathbf{C}}\right) \mathbf{L}+\overline{\mathbf{D}} \overline{\mathbf{W}} \overline{\mathbf{D}}^{T} \\
0=\mathbf{K}\left(\overline{\mathbf{A}}+\overline{\mathbf{B}} \mathbf{G}_{a} \overline{\mathbf{C}}\right)+\left(\overline{\mathbf{A}}+\overline{\mathbf{B}} \mathbf{G}_{a} \overline{\mathbf{C}}\right)^{T} \mathbf{K}+\overline{\mathbf{C}}^{T} \mathbf{G}_{a}{ }^{T} \mathbf{F}_{3} \mathbf{G}_{a} \overline{\mathbf{C}}+\overline{\mathbf{Q}}
\end{gathered}
$$




$$
\text { where } \quad \bar{W}=\left[\begin{array}{ccc}
W & 0 & 0 \\
0 & v_{m} & 0 \\
0 & 0 & v_{p}
\end{array}\right]
$$

Since no closed form solution exists for these equations, they must be solved in an iterative fashion.

The necessity of using output feedback rather than state feedback in the SCAS control solution can be seen by studying the equations for the optimal pilot-model ( eqs. 6-8) and the SCAS (eqs. 22, 23, 25). The optimal pilot-model is basically a standard LQG (Linear Quadratic Gaussian) regulator and estimator, in which estimation of all the aircraft states is required for the model implementation. If the SCAS control was also based upon state feedback, it would require state estimation of both the aircraft states and the optimal pilotmodel states. On the next design iteration, the optimal pilot-model would then require estimation of both the aircraft states and the controller states, the dimension of which has been increased due to the necessity of state estimation in the SCAS. This would produce an increase in the number of states on every design iteration. The problem is avoided through the use of output feedback in the SCAS design; no additional states are introduced by the SCAS, and the problem remains of fixed order.

\subsection{CCS Design Variable Simplification}

The design variables in the CCS methodology are $\mathbf{Q}_{p}, \mathbf{R}_{1}, \mathbf{R}_{2}, \mathbf{W}, \mathbf{V}_{p}, \mathbf{V}_{m}, \mathbf{Q}_{a}, \mathbf{F}_{1}$, $\mathbf{F}_{2}$, and $\mathbf{F}_{3}$. Even when all of the matrices are considered to be symmetric, the application of CCS to an aircraft model with six degrees of freedom and four control effectors will yield 178 individual matrix elements to be specified. At first glance, this appears to be an unreasonably large number of variables to use the design method on any large-order problem. However, constraints imposed through use of the pilot-model and other logical choices in the design variables lead to a far more simplified choice of design variables. This section will describe the simplifications which were made.

The most direct source of simplification comes from matching parameters in the optimal pilot-model. As was previously noted, certain constraints must be met to apply the optimal pilot-model properly. The first constraint is related to the pilot neuromuscular time lag, $r_{n}$, which has been experimentally determined to be within the range of .10 to .25 seconds. This can be achieved by adjusting the magnitude of the $\mathbf{R}_{2}$ matrix relative to $\mathbf{Q}_{p}$. The second constraint is related to the remnants of the pilot observations and control inputs; these constraints can be satisfied through selection of $V_{p}$ and $V_{m}$ relative to $W$. The last constraint from the pilot-model concerns the selection of the pilot state weighting matrix, $\mathbf{Q}_{p}$. The optimal pilot-model is only valid when $\mathbf{Q}_{p}$ is chosen to reflect the task which the pilot is performing. The selection of $Q_{p}$ will be discussed later; it should now be noted that the choice of design variables $Q_{p}, \mathbf{R}_{1}, \mathbf{R}_{2}, \mathbf{V}_{p}$, and $\mathbf{V}_{m}$ are effectively replaced through the choice of the neuromuscular time constant $\tau_{n}, \mathbf{R}_{1}$, and task description (or choice of $\mathbf{Q}_{p}$ ).

Selection of the matrices $Q_{a}, R_{1}, W, F_{1}, F_{2}$, and $F_{3}$ is also necessary. If we assume the main function of a SCAS is to reduce pilot workload with limited SCAS control activity, a logical choice of $Q_{a}, F_{1}$, and $F_{2}$ is:

$$
\begin{aligned}
& \mathbf{Q}_{a}=\mathbf{Q}_{p} \\
& \mathbf{F}_{\mathbf{1}}=\mathbf{R}_{\mathbf{1}} \\
& \mathbf{F}_{\mathbf{2}}=\mathbf{R}_{\mathbf{2}}
\end{aligned}
$$

This choice of matrices leads to the following objective functions: 


$$
\begin{gathered}
\mathbf{J}_{p}=\mathbf{E}\left\{\lim _{T \rightarrow \infty} \frac{1}{T} \int_{0}^{T}\left[\mathbf{x}^{T} \mathbf{Q}_{p} \mathbf{x}+\mathbf{u}_{p}{ }^{T} \mathbf{R}_{1} \mathbf{u}_{p}+\dot{\mathbf{u}}_{p}^{T} \mathbf{R}_{2} \dot{\mathbf{u}}_{p}\right] d t\right\} \\
\mathbf{J}_{a}=\mathbf{J}_{p}+\mathbf{E}\left\{\lim _{T \rightarrow \infty} \frac{1}{T} \int_{0}^{T}\left[\mathbf{u}_{a}{ }^{T} \mathbf{F}_{3} \mathbf{u}_{a}\right] d t\right\}
\end{gathered}
$$

As can be seen, with these choices of matrices, the aircraft objective function becomes the pilot objective function with an additional weighting term on the SCAS control activity.

With these design simplifications, the unspecified design variables become the matrices $\mathbf{Q}_{p}, \mathbf{R}_{1}, \mathbf{F}_{3}$, and $\mathbf{W}$, along with the neuromuscular time constant $\tau_{n}$. To study the effects of $\mathbf{R}_{1}, W$, and $\tau_{n}$, a thorough parametric study was made on the eighth-order helicopter model chosen for this application to determine the variation in control designs caused by variations in these parameters. The results indicate that the effect on the designs because of the parameter variations was minimal; therefore, $W$ and $R 1$ were chosen to be identity matrices, and $\tau_{n}$ was kept in the vicinity of $.15 \mathrm{sec}$ in the subsequent design work.

These simplifications result in two final design matrices, $\mathbf{Q}_{p}$ and $\mathbf{F}_{\mathbf{3}}$. As was previously mentioned, $\mathbf{Q}_{p}$ is chosen in the pilot-model to reflect the task description. In this design situation, $\mathbf{F}_{3}$ was varied as necessary to prevent saturation of the aircraft controls over the anticipated flight envelope of the aircraft. If these design matrices are further specified to be diagonal, then the final number of design variables drops to 12 for the problem specified here.

\subsection{Pseudoinverse Decoupling CCS Design Modification}

Initial design work done with the previously described CCS design method indicated that although the method produced good on-axis responses, it also had a tendency to produce some undesirable off-axis responses as well. A modification to the design process was needed which would preserve the on-axis responses while removing the undesirable off-axis responses. Many methods of altering the control design structure aimed at decoupling the final design were tested, but none were successful. The basic problem encountered was that every attempt to penalize the undesirable coupling in the objective functions led to indefinite weighting matrices, $Q_{p}$ and $F_{3}$. The CCS design method requires that $F_{3}$ be positive definite, and that $Q_{p}$ be positive definite or semidefinite.

Another method was developed (similar to one used in ref. 8) which consisted of defining the elements in the closed-loop aircraft and control matrices responsible for the undesired coupling present in the design. Additional feedback and feedforward gains $\mathbf{G}_{f b}$ and $\mathbf{G}_{f f}$ were produced by taking the pseudoinverse of each of the desired matrices. The equations are as follows:

$$
\begin{gathered}
\mathbf{A}_{\text {desired }}=\mathbf{A}_{\text {actual }}+\mathbf{B} \mathbf{G}_{f b} \\
\mathbf{B}_{\text {deoired }}=\mathbf{B}_{\text {actual }}+\mathbf{B} \mathbf{G}_{f f} \\
\mathbf{G}_{f b}=\mathbf{B}^{\dagger}\left(\mathbf{A}_{\text {deoired }}-\mathbf{A}_{\text {actual }}\right) \\
\mathbf{G}_{f f}=\mathbf{B}^{\dagger}\left(\mathbf{B}_{\text {desired }}-\mathbf{B}_{\text {actual }}\right)
\end{gathered}
$$

where $\mathbf{B}^{\dagger}$ is the pseudoinverse of $\mathbf{B}$, defined as:

$$
\mathbf{B}^{\dagger}=\left(\mathbf{B}^{T} \mathbf{B}\right)^{-1} \mathbf{B}^{T}
$$


The modified SCAS design is then found by partitioning the SCAS control matrix $\mathbf{G}_{a}$ into feedback and feedforward components $\mathbf{G}_{x x}$ and $\mathbf{G}_{u u}$, and combining them with the new gains obtained above:

$$
\begin{aligned}
& \mathbf{G}_{a}=\left[\begin{array}{ll}
\mathbf{G}_{x \boldsymbol{x}} & \mathbf{G}_{u u}
\end{array}\right] \quad \text { (unmodified CCS SCAS design) } \\
& \mathbf{G}_{\text {modified }}=\left[\begin{array}{ll}
\mathbf{G}_{x x}+\mathbf{G}_{f b} & \mathbf{G}_{u u}+\mathbf{G}_{f f}
\end{array}\right] \quad \text { (modified CCS design) }
\end{aligned}
$$

\section{EXPERIMENT DESIGN}

\subsection{Simulation Vehicle/Model}

The control-system design methodologies were applied to a linearized, 6 degree of freedom model of the Boeing Vertol CH-47 helicopter (ref. 9). The CH-47 was chosen because of interest in using a variable-stability $\mathrm{CH}$ 47 helicopter at NASA for eventual in-flight controlsystem design evaluations. The CH-47 is a tandem rotor helicopter with a maximum gross weight of 38000 $\mathrm{lb}$, and is chiefly used as a transport-type aircraft (fig. 3). The trim data and linearized model used were for a 60 knot levelflight reference condition. The linear model is described in Appendix I, and

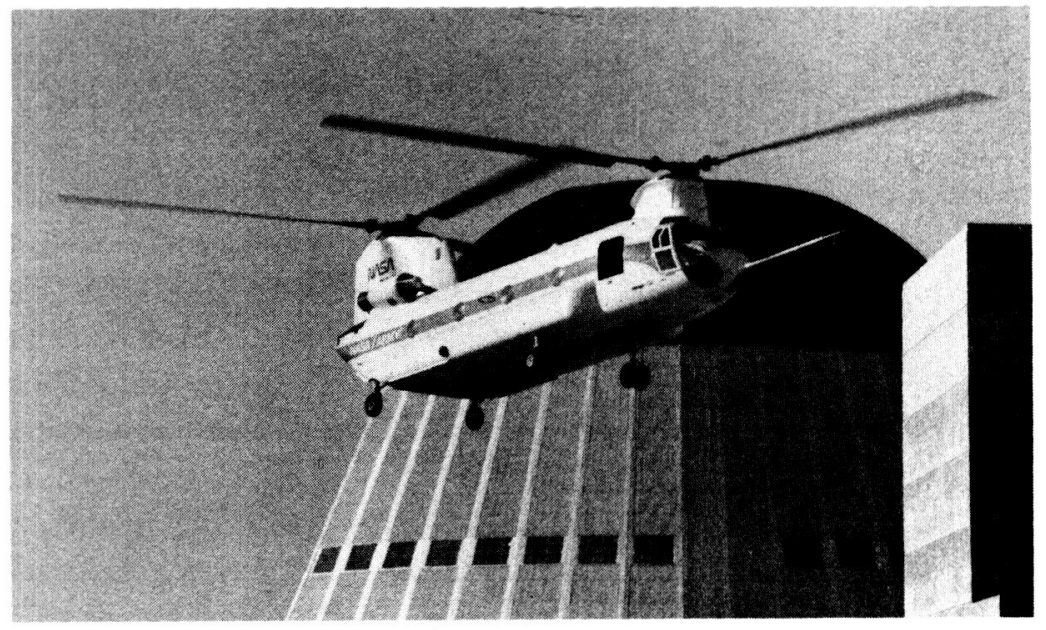

Figure 3 - CH-47 Helicopter a summary of the open-loop eigenvalues is presented in table.1. The aircraft states of translational velocity $(u, v, w)$ are expressed in $\mathrm{ft} / \mathrm{sec}$ attitudes $(\phi$ and $\theta$ ) in degrees, and angular rates $(p, q, r)$ in $\mathrm{deg} / \mathrm{sec}$. These choices of units were made to provide some rough equivalence in the weightings between translational rates, angular rates, and attitudes. Control displacements are all measured in inches.

As can be seen from table 1 , the open-loop dynamics of the CH-47 includes two unstable modes, the most unstable of which is real $(\lambda=.53)$ and consists of large longitudinal velocity $(u)$ and pitch $(\theta)$ variations. The second unstable mode is a complex pair ( $\omega$ $=.54, \varsigma=-.16)$ constituting a

\begin{tabular}{|c|c|c|c|}
\hline$\lambda$ & $\omega_{n}$ & $\zeta$ & Principal Characteristics \\
\hline \hline .532 & - & - & long. velocity and pitch \\
\hline-.059 & - & - & spiral \\
\hline-1.31 & - & - & roll \\
\hline-2.36 & - & - & heave-pitch \\
\hline- & .54 & -.16 & dutch-roll \\
\hline- & .36 & .46 & phugoid \\
\hline
\end{tabular}
dutch-roll mode. Clearly, the Table 1 - OPEN-LOOP basic aircraft is in need of some type of stability augmentation and is an excellent choice for design evaluation.

\subsection{Control-System Designs}

The task chosen for this application was the execution of an Instrument Landing System (ILS) approach in the presence of a disturbance. The pilot task in this case can be described 
as limiting perturbations about the trimmed state in the presence of an external disturbance, which for the design case was assumed to be a white noise input to the control effectors.

The following section describes the four design methods which were employed to design a SCAS for the CH-47 helicopter, and the resulting designs. The first two methods described are the unmodified and modified CCS methods, which will be respectively referred to as CCS1 and CCS2. The other two methods are Linear Quadratic Regulator (LQR) theory and classical/frequency-domain (FD) theory.

\subsubsection{Unmodified CCS Design (CCS1)}

In addition to $\mathbf{Q}_{p}$ and $\mathbf{F}_{3}$, the matrices $\mathbf{B}_{a}, \mathbf{W}, \mathbf{C}_{p}, \mathbf{C}_{x}$, and $\mathbf{C}_{u}$ have to be specified before applying the CCS design methodology. The following assumptions were made:

1) The pilot control input and aircraft input matrices are the same $\left(\mathbf{B}_{p}=\mathbf{B}_{a}=\mathbf{B}\right)$. This is a reasonable assumption since there are not any additional control effectors available for the SCAS design.

2) The aircraft disturbances were in the form of control input perturbations $(D=B)$. In the parametric variations done during the simplification process, it was noted that the resulting designs were relatively insensitive to the choice of $\mathbf{D}$.

3) Full state feedback was available for pilot observation $\left(C_{p}=I\right)$. The availability of all the aircraft states for pilot observation is reasonable under instrument conditions.

4) All of the aircraft states and the pilot control inputs were available for feedback $\left(C_{x}{ }^{T}=\left[\begin{array}{ll}I & 0\end{array}\right] ; \mathbf{C}_{u}{ }^{T}=\left[\begin{array}{ll}0 & I\end{array}\right]\right)$. This assumption was made in order to allow direct comparison with the LQR control (full state feedback).

As was indicated in the description of the CCS method, the pilot state covariance weighting matrix $Q_{p}$ must be chosen to reflect the task being performed. In this case, $\mathbf{Q}_{p}$ was chosen to describe the execution of an ILS approach. Several iterations of choice were made, and evaluated by the author in piloted simulations until a $\mathbf{Q}_{p}$ matrix was found which seemed to adequately describe the task. In all of these control designs, the matrix $\mathbf{F}_{3}$ was adjusted to prevent saturation of the controls within the expected range of flight conditions for the aircraft. Following is a description of the iterations on the choice of $\mathbf{Q}_{\boldsymbol{p}}$ :

Design I - The first choice of $Q_{p}$ was based on the philosophy that the main desire of the pilot in a regulation task is to stabilize the aircraft about the trim point, or maintain constant pitch $(\theta)$ and roll $(\phi)$ attitude while minimizing sideslip $(\beta)$. Therefore, the first choice of $Q_{p}$ was made with unity weighting on $\theta, \phi$, and $\beta$ (equating to a weighting value of 0.328 on $v$ covariance).

Design II - When Design I was evaluated in the simulator, several areas contributing to pilot workload were identified. Airspeed control was difficult, and workload in the lateral directional axes was high due to oscillatory responses in both roll and yaw. Weightings were therefore placed on the longitudinal speed $u$ (.02), roll-rate $p(0.5)$, and yaw-rate $r(0.5)$ covariances in the second design iteration.

Design III - Although pilot workload was greatly reduced with Design II, oscillatory responses were still present in the pitch and roll axes. Also, a high degree of turn coordination (due to weighting on $v$ ) made small heading adjustments difficult to achieve. Therefore, on the next design iteration, a weighting of 0.5 was placed on the pitch-rate $q$, roll-rate $r$ weighting was increased to 2.0 , and $v$ weighting was decreased to .25 . 
Final CCS1 Design - The design resulting from the weighting choices discussed above was considered to be a satisfactory control-system, since no very high workload areas could be isolated. This design was used for the final simulator evaluation with the other control designs. A listing of control gains is given in Appendix II, and the closed-loop eigenvalues are shown in table 2.

\begin{tabular}{|c|c|c|c|}
\hline$\lambda$ & $\omega_{n}$ & $\varsigma$ & Principal Characteristics \\
\hline \hline .005 & - & - & longitudinal velocity \\
\hline-3.17 & - & - & heave-pitch \\
\hline- & .98 & .59 & dutch roll \\
\hline- & .785 & .78 & heave-pitch \\
\hline- & 1.25 & .96 & roll \\
\hline
\end{tabular}

Table 2 - CCS1

\subsubsection{Modified CCS Design (Pseudoinverse Method - CCS2)}

One problem which was encountered with the CCS1 design method was the degree of coupling (longitudinal-to-lateral and longitudinal-to-vertical) present in the closedloop design. Another control-system was designed using the pseudoinverse method described earlier in which some of the longitudinal-to-lateral and pitch-to-heave couplings were removed. The "desired" aircraft matrix was formed from the closed-loop matrix by removing all the pitch-rate/lateral coupling elements $\left(M_{\beta}, M_{p}, M_{\phi}\right.$, and $M_{r}$ ), and the pitch-rate due to heave $\left(\mathrm{M}_{w}\right)$ term. The "desired" control matrix was formed by removing the pitch-

\begin{tabular}{|c|c|c|c|}
\hline$\lambda$ & $\omega_{n}$ & $\zeta$ & Principal Characteristics \\
\hline-.021 & - & - & longitudinal velocity \\
\hline-.547 & - & - & heave \\
\hline-1.57 & - & - & heave-pitch \\
\hline-2.18 & - & - & heave-pitch \\
\hline- & 1.09 & .61 & dutch roll \\
\hline- & 1.15 & .99 & roll \\
\hline
\end{tabular}

Table 3 - CCS2

rate/collective coupling term $\mathbf{M}_{\delta_{0}}$. The resulting control design was used for evaluation in the piloted simulations, and will hereafter be referred to as CCS2. The resulting control gains are presented in Appendix II, and the closed-loop eigenvalues are shown in table 3 .

\subsubsection{Linear Quadratic Regulator Design (LQR)}

In addition to the previously described CCS designs, it was desired to compare with a design obtainable using standard LQR theory. The equations used in the formulation of the LQR design follow.

The aircraft dynamics are expressed as:

$$
\dot{\mathbf{x}}=\mathbf{A x}+\mathbf{B u}
$$

If full state feedback is assumed, the control which minimizes the objective function $\mathbf{J}$ is found by solving the following equations:

$$
\begin{gathered}
\mathbf{0}=\mathbf{A} \mathbf{K}^{T}+\mathbf{K A}-\mathbf{K B R} \mathbf{R}^{-1} \mathbf{B}^{T} \mathbf{K}+\mathbf{Q} \\
\mathbf{G}=-\mathbf{R}^{-1} \mathbf{B}^{T} \mathbf{K} \\
\mathbf{J}=\mathbf{E}\left\{\lim _{T \rightarrow \infty} \frac{1}{T} \int_{0}^{T}\left[\mathbf{x}^{T} \mathbf{Q} \mathbf{x}+\mathbf{u}^{T} \mathbf{R u}\right] d t\right\} \\
\mathbf{u}=\mathbf{G} \mathbf{x}
\end{gathered}
$$


where $\mathbf{Q}$ and $\mathbf{R}$ are weighting matrices on the state and control covariances, respectively. The LQR theory was applied in a similar manner to the CCS, in that several iterations of weighting matrices were tested in piloted simulation by the author. In the first iteration, the weighting matrices $\mathbf{Q}$ and $\mathbf{R}$ were chosen to be the matrices obtained in the CCS1 design, $Q_{p}$ and $\mathbf{F}_{3}$. This choice was unsatisfactory due to saturation of all

\begin{tabular}{|c|c|c|c|}
\hline$\lambda$ & $\omega_{n}$ & $\zeta$ & Principal Characteristics \\
\hline \hline-.03 & - & - & longitudinal velocity \\
\hline-2.11 & - & - & heave-pitch \\
\hline- & .99 & .75 & heave-pitch \\
\hline- & 1.79 & .56 & dutch roll \\
\hline- & 1.37 & .95 & roll \\
\hline
\end{tabular}

Table 4 - LQR

the controls, and several adjustments were made until a satisfactory design was achieved. The final LQR design was tested along with the CCS1 and CCS2 designs. The control gains are given in Appendix II, and the closed-loop eigenvalues are shown in table 4.

3.2.4 Classical/Frequency-Domain Design (FD)

A control-system was designed by the author of reference 10 , using a priori knowledge of desirable characteristics for the defined task. The control gains for this design are shown in Appendix II, and the closed-loop eigenvalues are shown in table 5 .

\begin{tabular}{|c|c|c|c|}
\hline$\lambda$ & $\omega_{n}$ & $\zeta$ & Principal Characteristics \\
\hline \hline-.014 & - & - & longitudinal velocity \\
\hline-.57 & - & - & heave \\
\hline- & 1.61 & .57 & dutch roll \\
\hline- & 2.0 & .87 & roll \\
\hline- & 2.0 & .92 & heave-pitch \\
\hline
\end{tabular}

Table 5 - FD

\section{SIMULATION EXPERIMENT}

A piloted, fixed-base simulation was conducted on a NASA Ames simulator, using a full, nonlinear model of the CH-47 helicopter, developed by Boeing-Vertol (ref. 9). The simulation facility and evaluation tasks are described in the following sections.

\subsection{Simulation Facility}

The experiment was performed on the Chair 6 fixed-base simulator at NASA Ames Research Center. This simulator consisted of a single-seat cockpit cab equipped with conventional helicopter controls, and a typical instrument panel (fig. 4). A 600:1-scale terrain board and camera visual system were presented through the cab window on a color television monitor. The terrain board is shown in figure 5. The simulation was also set up with an ILS approach (with a six-degree glideslope) to one of the runways. Outer and middle markers and fog were also available. A more detailed description of the ILS approach is presented reference 11. A turbulence model was used to simulate the effects of turbulence when desired during the simulation, and is further described in reference 12.

The cockpit instrumentation consisted of a horizontal situation indicator (HSI), attitude director indicator (ADI), instantaneous vertical speed indicator (IVSI), and instruments to indicate turn and slip, airspeed, altitude (both barometric and radar), heading, and torque. Glideslope and localizer information were presented on both the ADI and HSI, and lights were provided to indicate passage over the outer and middle markers.

\subsection{Evaluation Tasks}

In addition to the ILS task, the control-systems were also evaluated in two other tasks. The reason for doing this was to determine the overall "robustness" of the controllers to 


\section{OF. POOR QUALTY}

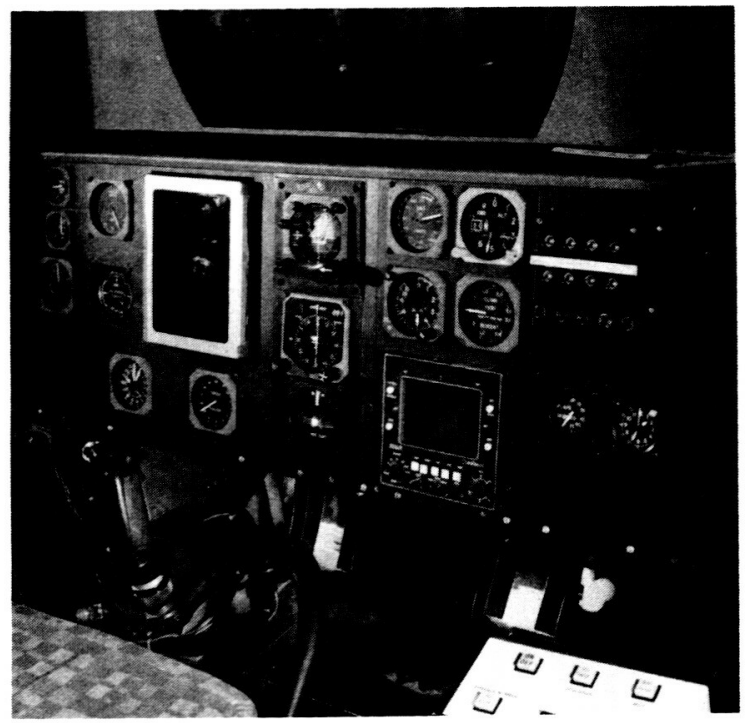

Figure 4 - Simulator Cockpit

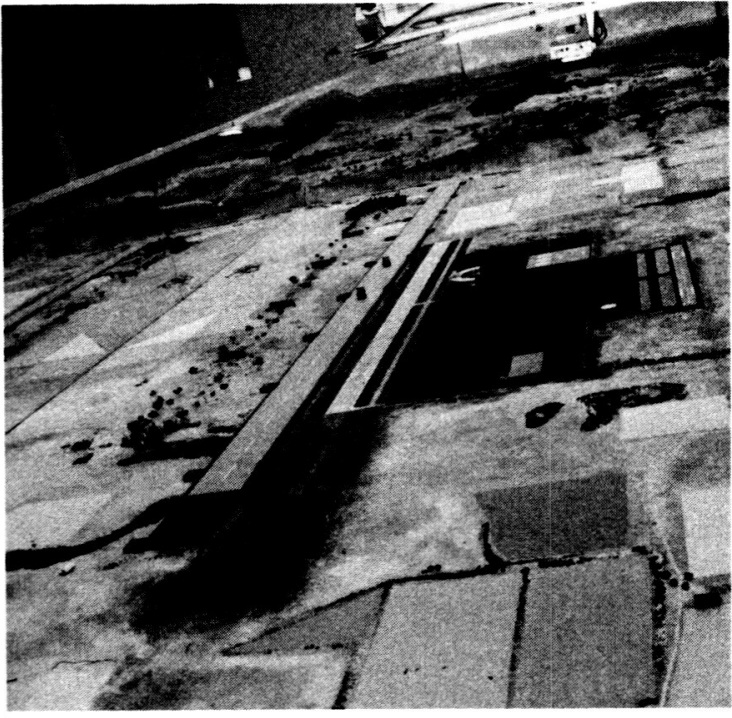

Figure 5 - Terrain Board

varying flight conditions and tasks. Since both the LQR and CCS controllers were designed to prevent control saturation from occuring within the flight envelope, it was a reasonable to evaluate the controller designs over a wide range of tasks. The evaluation tasks are described in more detail below.

Instrument Landing System (ILS) Task (figure 6a) - The ILS approach was the task for which the control-system was expressly designed. The approach began in a procedure turn to establish inbound localizer tracking at a 1000$\mathrm{ft}$ altitude. After intercepting a 6-degree glideslope, the pilot tracked the localizer and glideslope down to a $100-\mathrm{ft}$ altitude missedapproach point. A missedapproach procedure was executed, consisting of a climbing left turn to establish outOUTER

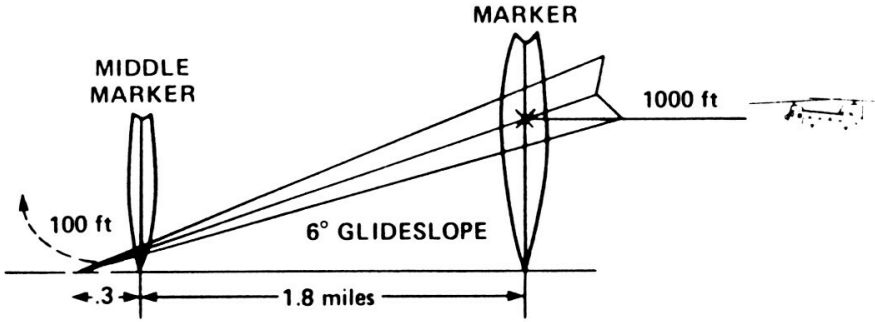

Figure 6a - ILS Approach Task

bound tracking on the localizer course. The maneuver ended when the pilot had intercepted the outbound localizer course. The localizer sensitivity was set at 1.4 degrees for full needle deflection, glideslope at 0.7 degrees full deflection. The desired performance consisted of localizer and glideslope within one-half full deflection when intercepted. At other times (procedure turn, missed approach) desired performance was: altitude control $\pm 100 \mathrm{ft}$, heading \pm 5 degrees, and standard rate turns $(3 \mathrm{deg} / \mathrm{sec}) \pm 1 / 2$ needle deflection. Airspeed control of $60 \pm 5$ knots was expected throughout the maneuver. This task was performed entirely under instrument meteorological conditions (IMC).

Slalom Task (figure 6b) - The purpose of the slalom task was to expose the lateraldirectional characteristics of the aircraft. The pilot was instructed to fly between the markers on a runway. The desired performance criterion consisted of ground path control within $10 \mathrm{ft}$, altitude at $30 \pm 10 \mathrm{ft}$, and airspeed $60 \pm 5$ knots. This task was performed entirely under visual meteorological conditions (VMC). 


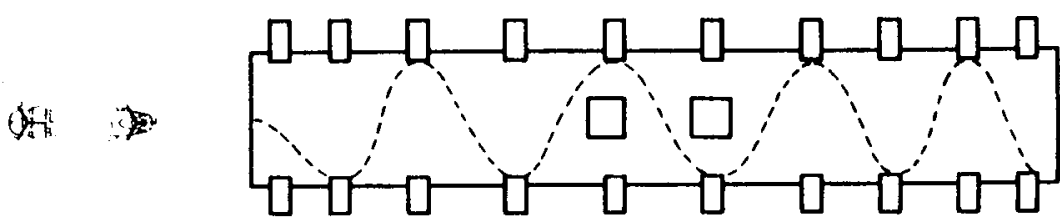

Figure 6b - Slalom Task

Nap-of-the-Earth (NOE) Task (figure 6c) - The purpose of the NOE task was to expose the longitudinal characteristics of the aircraft. The pilot was instructed to fly at a constant heading over a series of 50 - $\mathrm{ft}$ berms. Desired performance consisted of heading control \pm 10 degrees, altitude $20 \pm 10 \mathrm{ft}$ except over the berms (minimizing exposure over berms), and airspeed $60 \pm 5$ knots. This was also performed under VMC.

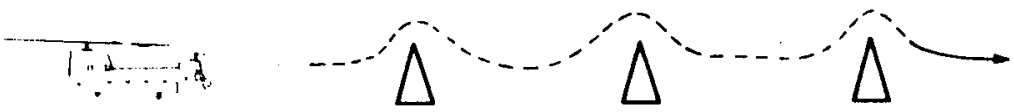

Figure 6c - Nap-of-the-Earth Task

In all of these tasks, adequate performance was defined by doubling the desired performance tolerances. Based on these desired and adequate performance measures, the pilot was asked to make comments about each configuration and assign a Cooper-Harper handling qualities rating (ref. 13). The Cooper-Harper rating scale is shown in figure 7. In addition to pilot ratings and comments, time histories of control positions, controller activity, and aircraft parameters were made on each run. After sufficient practice on each configuration, the pilot was asked to fly two attempts (with a pilot option for a third) before making comments and assigning a rating.

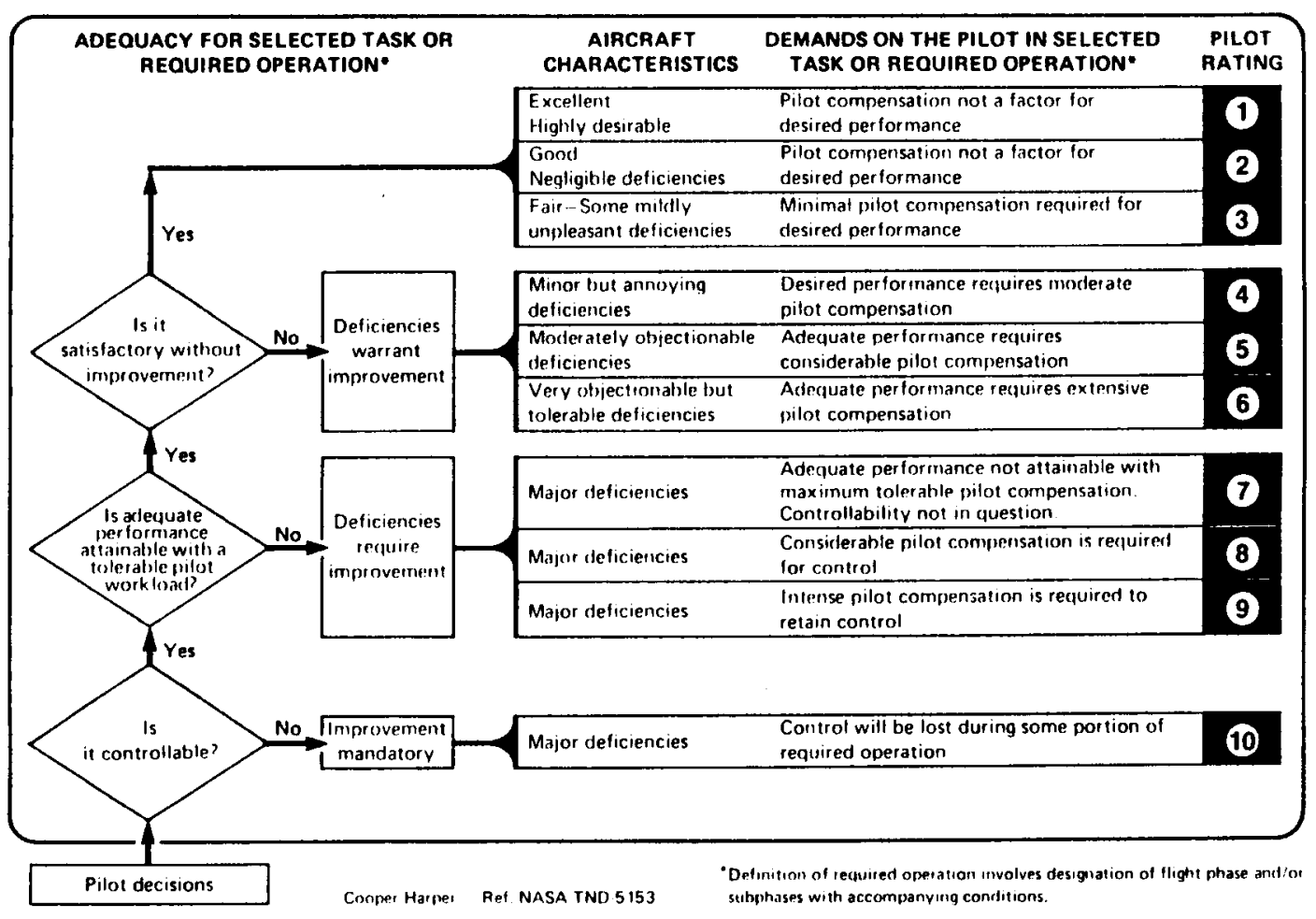

Figure 7 - Cooper-Harper Handling Qualities Rating Scale 


\section{RESULTS}

The evaluation maneuvers were all flown by a NASA research test pilot. A summary of the Cooper-Harper pilot ratings is presented in table 6.

\begin{tabular}{|r|c|c|c|c|}
\hline Augmentation & \multicolumn{4}{|c|}{ TASK } \\
\cline { 2 - 5 } Type & NOE & Slalom & ILS w/o turb & ILS with turb \\
\hline OPEN-LOOP & 5 & 6 & 8 & $*$ \\
CCS1 & 3 & 4 & 3 & 4 \\
CCS2 & 3 & 3 & 2.5 & 3 \\
LQR & 3 & 3 & 3 & 5 \\
FD & 3 & 3 & 3 & 2 \\
\hline
\end{tabular}

Table 6.

The first point to note is that the open-loop aircraft clearly has poor handling qualities, and that some type of SCAS is indeed necessary. The second item of interest is that, overall, the handling quality ratings for all of the control-systems are surprisingly similar. However, the pilot comments and ratings expose some noticeable differences when comparing with the baseline FD controller.

The FD control produced satisfactory handling quality ratings; the pilot commented that it was easy to fly, and had excellent attitude and altitude control. In comparison, the LQR control was also satisfactory until it was evaluated on the ILS task with turbulence, in which the performance was degraded to adequate. The pilot commented that, overall, the response was somewhat sluggish although fairly predictable. The
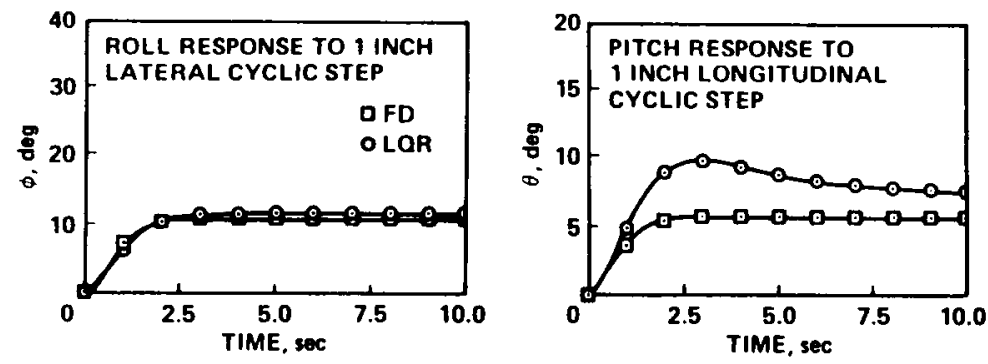

Figure 8 - Time Histories of FD and LQR Controllers differences in the two systems can be seen by looking at some representative time responses. Time history responses of pitch attitude to longitudinal cyclic input and bank angle to lateral cyclic input for both the FD and LQR controllers are shown in figure 8.

As can be seen, the roll attitude to lateral cyclic responses of the two controllers are nearly identical. However, the pitch attitude responses to longitudinal cyclic are clearly different. The FD control exhibited a fairly constant steady-state response to a step input, while the LQR control response tended to wash out over time. Although this was apparently not a problem in the first three evaluation tasks, the pilot did not find it to be satisfactory for the ILS task when subjected to an external disturbance.

Like the LQR controller, the CCS1 controller received ratings in the range of satisfactory to adequate, depending on the task. Performance on both the NOE and ILS without turbulence was considered to be satisfactory, while the performance on the slalom and ILS with turbulence was only adequate. The difference in the two controllers characteristics are again evident in the time histories. The plots presented in figure 9 show the response of
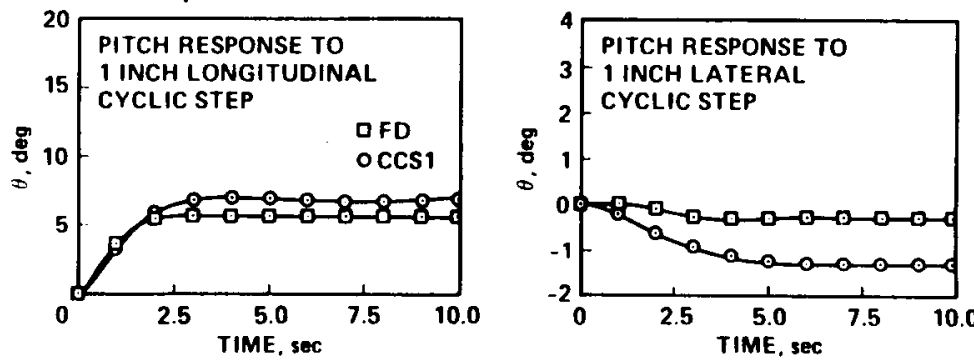

Figure 9 - Time Histories of FD and CCS1 Controllers pitch attitude to both longitudinal cyclic and lateral cyclic inputs for the FD and CCS1 designs. 
While the on-axis longitudinal response (pitch attitude to longitudinal cyclic) is similar, a large off-axis (pitch attitude to lateral cyclic) response is apparent in the CCS1 design. This characteristic makes the slalom task difficult to perform, since the helicopter pitches up and down with lateral stick inputs. This was substantiated by pilot comments on poor airspeed and altitude control. This off-axis response would also have been excited by the turbulence in the ILS task, accounting for the poor rating in that task. Although other offaxis effects were apparent with this controller, the most predominant was the one described above.

The modified CCS design (CCS2) received comparable pilot ratings to the FD design in all of the evaluation tasks, and similar pilot comments. One comment the pilot made specifically about the CCS2 design was that it appeared to have better disturbance rejection capabilities than other designs when flown in turbulence. The similarity of ratings and comments is not surprising when looking at the time histories of the two controllers; a representative sample is presented in figure 10 . What is interesting to note is that the time histories and closed-loop modes are so similar, consid-
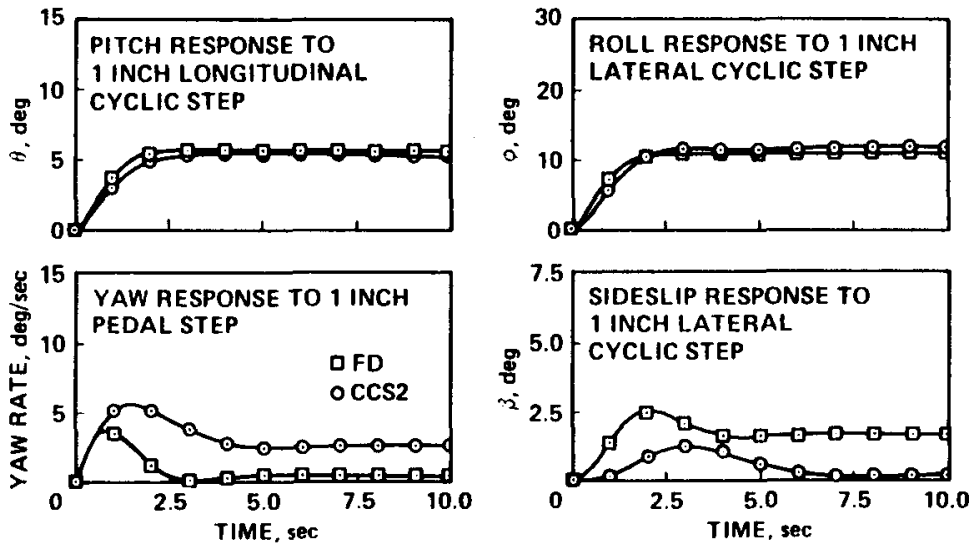

Figure 10 - Time Histories of FD and CCS2 Controllers ering they were derived using two completely different methods. The most major difference in the modal characteristics of the two control-systems is that the FD has a complex pitch mode $(\omega=2.0, \varsigma=.92)$, while CCS2 has a pair of real roots $(\lambda=-1.6$ and -2.2$)$ with the same basic mode shape. The other modes are nearly identical. The similarities in both the time responses and modal characteristics is even more surprising when the feedback and feedforward gains of the controllers are compared - they are noticeably different. The great similarity in the responses and characteristics of the two controllers lends a high degree of validation to the CCS design process. The modified CCS design process yielded a control very similar to the one created with existing, known design methods.

\section{CONCLUSIONS}

The results of this experiment established the general validity of the CCS design process. With slight modifications to the CCS design process, satisfactory handling qualities were achieved, and a design comparable to accepted frequency-domain methods and better than basic LQR methods was obtained in the absence of detailed a priori design criteria. Demonstrated advantages of the modified CCS design method include:

1) Elimination of detailed a priori design criteria through use of pilot modelling

2) Simple design method and control structure

3) Easily achieved decoupling

4) Ease of handling high-order models

The CCS design method can be applied to very high order models for which traditional design methods become difficult to use, such as models with aeroelastic modes or rotor states. As such, it is well suited for multiple controller designs, such as simultaneous designs 
of SCAS and engine controllers, which could become a very practical usage since current trends indicate a future emphasis on total integration of aircraft control-systems (instead of the current method of autonomous designs).

\section{REFERENCES}

1. Kriendler, E., Model-Following in Linear Quadratic Optimization.

Rothschild, D. $\quad$ AIA A Journal, Vol. 14, No. 7, July 1976, pp. 835-842

2. Innocenti, M., Quadratic Optimal Cooperative Control Synthesis

Schmidt, D.K. with Flight Control Application.

AIA A J. Guidance Contr., Vol. 7, No. 2, Mar.-Apr. 1984, pp. 206-214

3. McRuer, D.T., Dynamic Response of Human Operators.

Krendel, E.S. WADC TR-56-524, Oct. 1957, pp. 1-15

4. Kleinman, D.L., An Optimal Control Model of Human Response

Baron, S., Part I: Theory and Validation.

Levison, W.H. Automatica, Vol. 6, pp. 357-369

5. Kleinman, D.L., A Control Theoretic Approach to Manned-Vehicle

Baron, S., Systems Analysis.

Levison, W.H. IEEE Trans. Automatic Contr., Vol. AC-16, No. 16, Dec. 1971, pp. 824-832

6. Phatak, A., Identification of a Modified Optimal Control Model

Weinert, H., for the Human Operator.

Segall, I., $\quad$ Automatica, Vol. 12, 1976, pp. 31-41

Day, C.N.

7. Levine, W.S., On the Determination of the Optimal Constant Output

Athans, $M$.

Feedback Gains for Linear Multivariable Systems.

IEEE Trans. Automatic Contr. Vol. AC-15, No. 1,

Feb. 1970, pp. 44-48

8. Lebacqz, J.V., Design and Flight Test of a Decoupled Velocity Control System.

Chen, R.T.N.

AIAA Atmospheric Flight Mechanics Conference,

Hollywood, Florida, Aug. 1977

9. Weber, J.M., A Mathematical Simulation Model of a CH-47 Helicopter.

Tung, Y.L., $\quad$ NASA TM-84351, 1984.

Chung, $W$.

10. Lebacqz, J.V. Ground Simulation Investigation of Helicopter Decelerating

Instrument Approaches.

J. Guidance, Contr., Dynamics Vol. 16, No. 5, Sept.-Oct. 1983,

pp. 330-338

11. Federal Aviation Airman's Information Manual - ILS Standard Characteristics

Administration and Terminology.

FAA (Continuous Periodical).

12. Parris, B.L. Modeling Turbulence for Flight Simulators at NASA Ames.

NASA NAS2-7806, Jan. 1975.

13. Cooper, G.E., The Use of Pilot Rating in the Evaluation of

Harper, R.P.

of Aircraft Handling Qualities.

NASA TN D-5153, 1969 


\section{APPENDIX I}

\section{CH-47 Linear Model}

The linearized equations are expressed in state-space form as $\dot{\mathbf{x}}=\mathbf{A x}+\mathbf{B u}$ All parameters are in body-fixed coordinates.

Velocities are expressed in $\mathrm{ft} / \mathrm{sec}$, angular rates in $\mathrm{deg} / \mathrm{sec}$, and angles in degrees.

$$
\begin{aligned}
& \mathbf{x} \equiv\left\{\begin{array}{c}
u \\
w \\
q \\
\theta \\
v \\
p \\
\phi \\
r
\end{array}\right\}=\left\{\begin{array}{c}
\text { longitudinal velocity } \\
\text { vertical velocity } \\
\text { pitch-rate } \\
\text { pitch attitude } \\
\text { lateral velocity } \\
\text { roll-rate } \\
\text { bank angle } \\
\text { yaw-rate }
\end{array}\right\} \quad \mathbf{u} \equiv\left\{\begin{array}{c}
\delta_{e} \\
\delta_{a} \\
\delta_{c} \\
\delta_{r}
\end{array}\right\}=\left\{\begin{array}{c}
\text { longitudinal cyclic } \\
\text { lateral cyclic } \\
\text { collective } \\
\text { pedal }
\end{array}\right\} \\
& \mathbf{A}=\left[\begin{array}{cccccccc}
-0.009 & 0.034 & 0.046 & -0.561 & 0.001 & 0.000 & 0.000 & -0.001 \\
-0.076 & -0.564 & 1.757 & -0.029 & 0.002 & -0.001 & 0.002 & -0.003 \\
-0.416 & 0.831 & -1.582 & 0.000 & -0.074 & 0.020 & 0.000 & -0.274 \\
0.000 & 0.000 & 1.000 & 0.000 & 0.000 & 0.000 & 0.000 & 0.004 \\
-0.001 & 0.004 & -0.002 & 0.000 & -0.072 & -0.035 & 0.561 & -1.773 \\
-0.039 & 0.113 & -0.092 & 0.000 & -0.532 & -1.058 & 0.000 & -0.121 \\
0.000 & 0.000 & 0.000 & 0.000 & 0.000 & 1.000 & 0.000 & 0.052 \\
0.013 & -0.009 & -0.057 & 0.000 & 0.001 & -0.087 & 0.000 & -0.073
\end{array}\right] \\
& \mathbf{B}=\left[\begin{array}{cccc}
0.048 & 0.000 & 0.328 & 0.000 \\
0.843 & 0.000 & -8.151 & 0.000 \\
23.597 & 0.001 & 13.394 & 0.006 \\
0.000 & 0.000 & 0.000 & 0.000 \\
0.941 & 1.085 & 0.063 & -0.044 \\
1.975 & 29.036 & 0.011 & -3.430 \\
0.000 & 0.000 & 0.000 & 0.000 \\
1.824 & 2.626 & 0.262 & 10.692
\end{array}\right] \\
& \text { Trim Condition: }\left\{\begin{array}{l}
U_{0} \\
W_{0} \\
Q_{0} \\
\Theta_{0} \\
V_{0} \\
P_{0} \\
\Phi_{0} \\
R_{0}
\end{array}\right\}=\left\{\begin{array}{cc}
100.26 & \mathrm{ft} / \mathrm{sec} \\
5.18 & \mathrm{ft} / \mathrm{sec} \\
0.0 & \mathrm{deg} / \mathrm{sec} \\
2.96 & \mathrm{degrees} \\
0.0 & \mathrm{ft} / \mathrm{sec} \\
0.0 & \mathrm{deg} / \mathrm{sec} \\
-.244 & \mathrm{degrees} \\
0.0 & \mathrm{deg} / \mathrm{sec}
\end{array}\right\} \quad\left\{\begin{array}{l}
\delta_{e 0} \\
\delta_{a 0} \\
\delta_{c 0} \\
\delta_{r 0}
\end{array}\right\}=\left\{\begin{array}{ccc}
-1.82 & \text { in. } \\
.197 & \text { in. } \\
4.745 & \text { in. } \\
.259 & \text { in. }
\end{array}\right\} \\
& \text { Maximum Control Deflections: } \quad\left\{\begin{array}{l}
\delta_{e \max } \\
\delta_{a \max } \\
\delta_{c \max } \\
\delta_{r \max }
\end{array}\right\}=\left\{\begin{array}{cc} 
\pm 6.5 & \text { in. } \\
\pm 4.18 & \text { in. } \\
0-9.12 & \text { in. } \\
\pm 3.6 & \text { in. }
\end{array}\right\}
\end{aligned}
$$


APPENDIX II

Control-System Gains

Control Law: $\mathbf{u}=\mathbf{G}_{f b} \mathbf{X}+\mathbf{G}_{f f} \mathbf{u}_{p}$

CCS1

$$
\begin{gathered}
\mathbf{G}_{f b}=\left[\begin{array}{cccccccc}
.016 & -.006 & -.077 & -.122 & .006 & -.005 & -.005 & -.018 \\
0.0 & 0.0 & .002 & .002 & -.003 & -.046 & -.068 & -.011 \\
.006 & -.002 & -.026 & -.042 & 0.0 & .001 & .002 & .002 \\
0.0 & .001 & .003 & .004 & .028 & .009 & .020 & -.091
\end{array}\right] \\
\mathbf{G}_{f f}=\left[\begin{array}{cccc}
.836 & -.011 & -.087 & -.010 \\
-.005 & .866 & -.029 & .004 \\
-.05 & .006 & .972 & .004 \\
-.005 & .006 & .005 & .889
\end{array}\right]
\end{gathered}
$$

\section{CCS2}

$$
\begin{gathered}
\mathbf{G}_{f b}=\left[\begin{array}{cccccccc}
0.016 & -.033 & -.077 & -.122 & .004 & -.002 & -.001 & .009 \\
0.000 & 0.002 & 0.002 & 0.002 & -.002 & -.046 & -.069 & -.013 \\
.006 & -.005 & -.026 & -.042 & -.001 & .001 & .002 & .005 \\
-.001 & .005 & .003 & .004 & .029 & .008 & .019 & -.095
\end{array}\right] \\
\mathbf{G}_{f f}=\left[\begin{array}{cccc}
.836 & -.011 & -.526 & -.010 \\
-.006 & .866 & .042 & 0.007 \\
-.051 & .006 & .926 & .004 \\
-.005 & .006 & .072 & .888
\end{array}\right]
\end{gathered}
$$

$\underline{\text { LQR }}$

$$
\begin{gathered}
\mathbf{G}_{f b}=\left[\begin{array}{cccccccc}
.032 & -.031 & -.072 & -.126 & .004 & 0.0 & .002 & .006 \\
0.0 & -.002 & 0.0 & 0.0 & -.036 & -.051 & -.096 & .062 \\
-.023 & .023 & .033 & .032 & -.006 & 0.0 & -.001 & -.001 \\
-.002 & .002 & .004 & .002 & .116 & .011 & .038 & -.188
\end{array}\right] \\
\mathbf{G}_{f f}=\left[\begin{array}{cccc}
0.000 & 0.000 & 0.000 & 0.000 \\
0.000 & 0.000 & 0.000 & 0.000 \\
0.000 & 0.000 & 0.000 & 0.000 \\
0.000 & 0.000 & 0.000 & 0.000
\end{array}\right]
\end{gathered}
$$

FD

$$
\begin{gathered}
\mathbf{G}_{f b}=\left[\begin{array}{cccccccc}
.018 & -.036 & -.087 & -.175 & 0.000 & 0.000 & 0.000 & 0.000 \\
0.000 & 0.000 & 0.000 & 0.000 & 0.020 & -.087 & -.140 & -.015 \\
0.000 & 0.000 & 0.000 & 0.000 & 0.000 & 0.000 & 0.000 & 0.000 \\
0.000 & 0.000 & 0.000 & 0.000 & 0.121 & 0.000 & 0.051 & -.159
\end{array}\right] \\
\mathbf{G}_{f f}=\left[\begin{array}{cccc}
1.000 & 0.000 & -.568 & 0.000 \\
0.000 & 1.540 & 0.000 & .114 \\
0.000 & 0.000 & 1.000 & 0.000 \\
0.000 & -.378 & 0.000 & 1.030
\end{array}\right]
\end{gathered}
$$




\begin{tabular}{|c|c|c|c|}
\hline $\begin{array}{l}\text { 1. Report No. } \\
\text { NASA TM-88353 }\end{array}$ & 2. Government Accession No. & \multicolumn{2}{|c|}{ 3. Recipient's Coulog No. } \\
\hline \multirow{2}{*}{\multicolumn{2}{|c|}{$\begin{array}{l}\text { 4. Title and Subtitle } \\
\text { THE APPLICATION OF QUADRATIC OPTIMAL COOPERATIVE } \\
\text { CONTROL SYNTHESIS TO A CH-47 HELICOPTER }\end{array}$}} & \multicolumn{2}{|c|}{$\begin{array}{l}\text { 5. Report Date } \\
\text { September } 1986\end{array}$} \\
\hline & & \multicolumn{2}{|c|}{ 6. Performing Organization Code } \\
\hline \multicolumn{2}{|l|}{$\begin{array}{l}\text { 7. Author(s) } \\
\text { Barbara K. Townsend }\end{array}$} & \multicolumn{2}{|c|}{$\begin{array}{l}\text { 8. Performing Organization Report No. } \\
\text { A-86388 }\end{array}$} \\
\hline \multicolumn{2}{|c|}{ 9. Performing Organization Name and Address } & \multicolumn{2}{|l|}{ 10. Work Unit No. } \\
\hline \multicolumn{2}{|c|}{$\begin{array}{l}\text { Ames Research Center } \\
\text { Moffett Field, CA } 94035\end{array}$} & \multicolumn{2}{|c|}{ 11. Contract or Grant No. } \\
\hline 12. Sponsoring Agency Name and Addres & & \multicolumn{2}{|c|}{$\begin{array}{l}\text { 13. Type of Report and Period Covered } \\
\text { Technical Memorandum }\end{array}$} \\
\hline \multicolumn{2}{|c|}{$\begin{array}{l}\text { National Aeronautics and Space Administration } \\
\text { Washington, DC } 20546\end{array}$} & \multicolumn{2}{|c|}{$505-61-51$} \\
\hline \multicolumn{4}{|c|}{$\begin{array}{l}\text { 15. Supplementary Notes } \\
\text { Point of Contact: Barbara K. Townsend, Ames Research Center, M/S 211-2, } \\
\text { Moffett Field, CA 94035, (415)694-5563 or FTS 464-5563 }\end{array}$} \\
\hline \multicolumn{4}{|c|}{$\begin{array}{l}\text { 16. Abstract } \\
\text { A control-system design method, Quadratic Optimal Cooperative Control } \\
\text { Synthesis (CCS), is applied to the design of a Stability and Control Aug- } \\
\text { mentation System (SCAS). The CCS design method is different from other } \\
\text { design methods in that it does not require detailed a priori design criteria, } \\
\text { but instead relies on an explicit optimal pilot-model to create desired } \\
\text { performance. The design method, which was developed previously for fixed- } \\
\text { wing aircraft, is simplified and modified for application to a Boeing Vertol } \\
\text { CH-47 helicopter. Two SCAS designs are developed using the CCS design } \\
\text { methodology. The resulting CCS designs are then compared with designs } \\
\text { obtained using classical/frequency-domain methods and Linear Quadratic } \\
\text { Regulator (LQR) theory in a piloted fixed-base simulation. Results indicate } \\
\text { that the CCS method, with slight modifications, can be used to produce con- } \\
\text { troller designs which compare favorably with the frequency-domain approach. }\end{array}$} \\
\hline $\begin{array}{l}\text { 17. Kev Words (Suggested by Author(s)) } \\
\text { Helicopter } \\
\text { Optimal control } \\
\text { Pilot mode1 } \\
\text { Simulation } \\
\text { Handling qualities }\end{array}$ & $\begin{array}{l}\text { 18. Distribution St } \\
\text { Unlimited }\end{array}$ & ct Category & 08 \\
\hline $\begin{array}{l}\text { 19. Security Classif. (of this report) } \\
\text { Unclassified }\end{array}$ & $\begin{array}{l}\text { 20. Security Classif. (of this page) } \\
\text { Unclassified }\end{array}$ & $\begin{array}{c}\text { 21. No. of Pages } \\
23\end{array}$ & $\begin{array}{r}\text { 22. Price" } \\
\mathrm{AO} 2\end{array}$ \\
\hline
\end{tabular}

